University of Massachusetts Amherst

ScholarWorks@UMass Amherst

Chemistry Department Faculty Publication Series

Chemistry

1998

\title{
Determination of chloride by flow injection spectrophotometry with membrane reagent introduction
}

SJ Chalk

JF Tyson

Follow this and additional works at: https://scholarworks.umass.edu/chem_faculty_pubs

Part of the Chemistry Commons

\section{Recommended Citation}

Chalk, SJ and Tyson, JF, "Determination of chloride by flow injection spectrophotometry with membrane reagent introduction" (1998). ANALYTICA CHIMICA ACTA. 1064.

Retrieved from https://scholarworks.umass.edu/chem_faculty_pubs/1064 


\title{
Determination of chloride by flow injection spectrophotometry with membrane reagent introduction
}

\author{
Stuart J. Chalk ${ }^{1}$, Julian F. Tyson* \\ Department of Chemistry, University of Massachusetts, Box 34510, Amherst MA 01003-4510, USA
}

Received 25 August 1997; received in revised form 9 December 1997; accepted 15 December 1997

\begin{abstract}
A single line manifold incorporating three Nafion ${ }^{\mathbb{R}}$ membrane reactors has been developed for the sequential introduction of components of the mercuric thiocyanate/iron(III)/acid reagent for the determination of chloride. Nitric acid was introduced at the first reactor to give sufficient ionic strength to allow cation exchange of $\mathrm{FeSCN}^{2+}$ at the second reactor, and $\mathrm{Hg}^{2+}$ at the third reactor. The composition of the reagent was adjusted by control of the flow rates of donor and acceptor streams, reagent concentration and reactor length. Calibration over the range $0.3-25 \mu \mathrm{g} \mathrm{ml}^{-1}$ was possible, though the calibration function was curved. The manifold was used to determine chloride in river water and in pond water at concentrations of 8 and $47 \mu \mathrm{g} \mathrm{ml}^{-1}$, respectively and gave results that were not significantly different from those obtained by an EPA method. The lower range sensitivity was 0.032 absorbance $\mu \mathrm{g} \mathrm{ml}^{-1}$, which compares favorably with that of other flow injection methods, but the detection limit was $300 \mathrm{ng} \mathrm{ml}^{-1}$, considerably higher than that can be achieved by flow injection procedures. This was due to the presence of mixing noise caused by fluctuations in reagent concentration related to pulsations in the flow in both donor and acceptor streams. Valve switching and refractive index effects were absent.
\end{abstract}

Keywords: Chloride determination; Nafion membrane; Flow injection

\section{Introduction}

A fundamental feature of a flow injection (FI) procedure, in which the product of an on-line reaction is monitored, is the dilution of the sample solution by the reagents. The resulting loss in sensitivity can be minimized by appropriate manifold optimization [1]. In principle, dilution of the sample can be avoided by the use of reagent phases other than homogeneous

\footnotetext{
*Corresponding author. Fax: 0014134544490

${ }^{1}$ Present address: Department of Natural Sciences, University of North Florida, 4567 St. Johns Bluff Road S., Jacksonville, FL 32224.
}

solutions and a number of solid reagents have been used in FI procedures. The most widely used are probably cadmium reactors for the spectrophotometric determination of nitrate, but there are a number of applications involving other metal reductors [2], immobilized enzymes [3], solid salts [4], polymerencapsulated reagents [5] and ionic reagents bound to ion-exchange resins [6]. Gaseous reagents have been introduced across membranes [7] and we recently described a method for the determination of phosphate [8] in which the molybdate reagent was transported across a supported liquid membrane and the reducing agent, hydrazine, was transported across a Nafion ${ }^{\mathbb{R}}$ membrane [9]. Although the feasibility of the 
approach was demonstrated, it was not practical to use the manifold for FIA.

In this paper, the introduction of reagents via Nafion membranes is further developed in a procedure for the FI spectrophotometric determination of chloride. The aim of the studies was to construct a manifold consisting of a single line between the injector and detector which passed through various membrane reactors at which appropriate reagent species were added, so that for sufficiently large sample volume, the dispersion coefficient would be unity, i.e. there would be no sample dilution at the peak maximum.

The procedure chosen to be adapted to this membrane introduction format was the widely used "mercury thiocyanate" method, introduced in 1952 $[10,11]$. Mercuric thiocyanate is added, the thiocyanate ion is displaced by chloride, the liberated thiocyanate reacts with iron(III) to form a red complex which may be detected between 450 and $480 \mathrm{~nm}$, depending on the presence and concentration of alcohols in the reagent which are added primarily to increase the solubility of mercuric thiocyanate. The method can achieve detection limits of a few $\mathrm{ng} \mathrm{ml}^{-1}$ if care is taken [12]. The adaptation to a FI format has been described in a number of papers [13-16]. As this procedure is so widely used, the reagent solution is typically available already formulated as a mixture of iron(III) nitrate, mercuric thiocyanate, nitric acid and methanol. To achieve a usable reagent composition in this work, the organic solvent was omitted and a system of three Nafion reactors was used. At the first of these, acid was added; at the second iron(III) thiocyanate (as $\mathrm{FeSCN}^{2+}$ ) was added and at the third reactor $\mathrm{Hg}^{2+}$ was added.

\section{Experimental}

\subsection{Apparatus}

Ultraviolet and visible spectrophotometric measurements were made using a Lambda VI spectrophotometer (Perkin Elmer, Norwalk, CT) which was interfaced to an IBM PS/2 (IBM, Armonk, NY). Atomic absorption measurements of iron and mercury were made using a Perkin Elmer 1100B spectrometer.

\subsection{Reagents}

All chemicals were obtained from Fisher (Fisher, Pittsburgh, PA) and were of analytical reagent grade. Doubly distilled 18 Mohm E-pure water (Barnstead, Dubuque, IA) was used throughout.

\subsection{Manifolds}

Flow injection manifolds were constructed using $0.8,0.5$ and $0.3 \mathrm{~mm}$ i.d. Teflon ${ }^{\circledR}$ tubing throughout (Upchurch, Oak Harbor, WA). Fittings were obtained form a variety of sources (Upchurch; Omnifit, New York, NY; FIA solutions, Gig Harbor, WA). A six-port Teflon Rheodyne valve (Supelco, Bellefonte, PA) was used to make injections. Pump tubing was purchased from Cole Parmer (Cole Parmer, Chicago, IL). Ismatec MS Reglo pumps (Ismatec SA, Switzerland) were used throughout. Membrane reactors, shown in Fig. 1, were made from Perma Pure dryer tubes (Perma Pure, Toms River, NJ) with suitable modification as previously described [8] and with the additional minor modification that, as the flanged ends of the Nafion tubing were easily deformed, a piece of microline tubing $(0.5 \mathrm{~mm}$ i.d.) was inserted into each end of the reactors to provide support. It had been found previously [8] that higher concentrations of the reagent species in the acceptor stream were produced when the donor and acceptor solutions flowed in opposite directions, and this configuration was used throughout.

\subsection{Method development}

Although the "chloride reagent" is formulated by dissolving ferric nitrate and mercuric thiocyanate in nitric acid, this method of preparation is not possible when the reagent species are to be introduced across membranes whose main mode of transport is by cation exchange. Although some sample materials may have sufficiently high ionic strength to provide a flow of cationic species from the sample stream to the reagent to preserve electrical neutrality, some samples (such as pristine waters) may not. The addition of an ionic strength adjustment buffer was not considered an acceptable approach, as this dilutes the analyte solution. Thus the strategy which was adopted was to add the acid first, as it was known from the previous work 


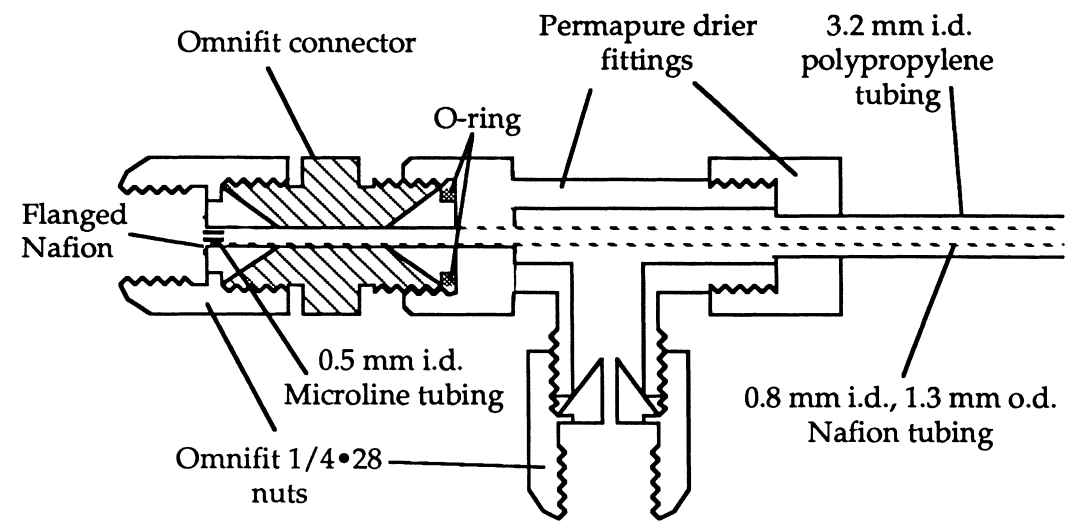

Fig. 1. Tubing connections for Nafion membrane reators.

[8] that acid would pass across Nafion into a pure water acceptor stream. The ionic strength of the sample stream was now sufficient to allow ionexchange transport of ionic species at the downstream reactors. At the first of these, $\mathrm{FeSCN}^{2+}$ was added. It is known that this species predominates, especially if excess iron is present $[17,18]$. Finally, at a third reactor $\mathrm{Hg}^{2+}$, was added.

The reagent concentrations needed for this determination, taken from four FI papers [13-15], are summarized in Table 1. The concentrations used by Tyson et al. [13] were taken as target values, as their manifold configuration gave the best sensitivity $(0.043$ absorbance $\mu \mathrm{g}^{-1} \mathrm{ml}$ ) of the four procedures. However, it was necessary to increase the acidity to about $0.1 \mathrm{M}$ to provide an ionic strength high enough for ion exchange of the $\mathrm{FeSCN}^{2+}$ and $\mathrm{Hg}^{2+}$ species. The performance of each reactor was studied separately in terms of the effects of the flow rates of acceptor and donor streams, and the reagent concentration. Reactor integrity was checked by measuring the fluid mass flow in both the donor and acceptor streams and, for the acid reactor, by analyzing the emerging donor and acceptor streams for chloride when a $100 \mu \mathrm{g} \mathrm{ml}^{-1}$ chloride solution was introduced. The concentration of thiocyanate in the acceptor stream was determined by injecting a discrete volume of the stream into a single line manifold for transport to the spectrometer for measurement of the absorbance at $454 \mathrm{~nm}$, on the basis that all the thiocyanate would be complexed with iron(III) and thus the absorbance of the $\mathrm{FeSCN}^{2+}$ complex could be related to the thiocyanate concentration. The concentrations of iron and mercury were determined by flame atomic absorption spectrometry using a similar single line manifold for transport to the spectrometer.

Table 1

Reagent concentrations for the flow injection determination of chloride using mercuric thiocyanate and iron(III)

\begin{tabular}{|c|c|c|c|c|}
\hline \multirow[t]{2}{*}{ Reagent component } & \multicolumn{4}{|c|}{ Concentrations of reagents } \\
\hline & Ruzicka et al. [15] & Krug et al. [16] & Van Staden [14] & Tyson et al. [13] \\
\hline Acid (nitric) & $4.65 \times 10^{-2} \mathrm{M}$ & $3.48 \times 10^{-2} \mathrm{M}$ & $2.85 \times 10^{-2} \mathrm{M}$ & $7.34 \times 10^{-3} \mathrm{M}$ \\
\hline Iron(III) & $\begin{array}{l}7.50 \times 10^{-2} \mathrm{M} \\
\left(4189 \mu \mathrm{g} \mathrm{ml}^{-1}\right)\end{array}$ & $\begin{array}{l}7.98 \times 10^{-4} \mathrm{M} \\
\left(45 \mu \mathrm{g} \mathrm{ml}^{-1}\right)\end{array}$ & $\begin{array}{l}1.78 \times 10^{-2} \mathrm{M} \\
\left(992 \mu \mathrm{g} \mathrm{ml}^{-1}\right)\end{array}$ & $\begin{array}{l}1.50 \times 10^{-2} \mathrm{M} \\
\left(838 \mu \mathrm{g} \mathrm{ml}^{-1}\right)\end{array}$ \\
\hline $\mathrm{Hg}(\mathrm{II})$ & $\begin{array}{l}1.98 \times 10^{-3} \mathrm{M} \\
\left(396 \mu \mathrm{g} \mathrm{ml}^{-1}\right)\end{array}$ & $\begin{array}{l}3.06 \times 10^{-4} \mathrm{M} \\
\left(61 \mu \mathrm{g} \mathrm{ml}^{-1}\right)\end{array}$ & $\begin{array}{l}9.21 \times 10^{-4} \mathrm{M} \\
\left(185 \mu \mathrm{g} \mathrm{ml}^{-1}\right)\end{array}$ & $\begin{array}{l}3.95 \times 10^{-4} \mathrm{M} \\
\left(79 \mu \mathrm{g} \mathrm{ml}^{-1}\right)\end{array}$ \\
\hline $\mathrm{SCN}^{-}$ & $\begin{array}{l}3.95 \times 10^{-3} \mathrm{M} \\
\left(229 \mu \mathrm{g} \mathrm{ml}^{-1}\right)\end{array}$ & $\begin{array}{l}6.11 \times 10^{-4} \mathrm{M} \\
\left(35 \mu \mathrm{g} \mathrm{ml}^{-1}\right)\end{array}$ & $\begin{array}{l}1.84 \times 10^{-3} \mathrm{M} \\
\left(107 \mu \mathrm{g} \mathrm{ml}^{-1}\right)\end{array}$ & $\begin{array}{l}7.88 \times 10^{-4} \mathrm{M} \\
\left(46 \mu \mathrm{g} \mathrm{ml}^{-1}\right)\end{array}$ \\
\hline Organic & $15 \% \mathrm{v} / \mathrm{v} \mathrm{EtOH}$ & $96 \% \mathrm{v} / \mathrm{v} \mathrm{EtOH}$ & $15 \% \mathrm{v} / \mathrm{v} \mathrm{MeOH}$ & $15 \%$ v/v $\mathrm{MeOH}$ \\
\hline Comments & $\begin{array}{l}\text { Fast single line } \\
\text { manifold }\end{array}$ & $\begin{array}{l}\text { Carrier and reagent } \\
96 \% \mathrm{v} / \mathrm{v} \mathrm{EtOH}\end{array}$ & $\begin{array}{l}\text { Double line high } \\
\text { concentrations }\end{array}$ & $\begin{array}{l}\text { Optimized double } \\
\text { line manifold }\end{array}$ \\
\hline
\end{tabular}




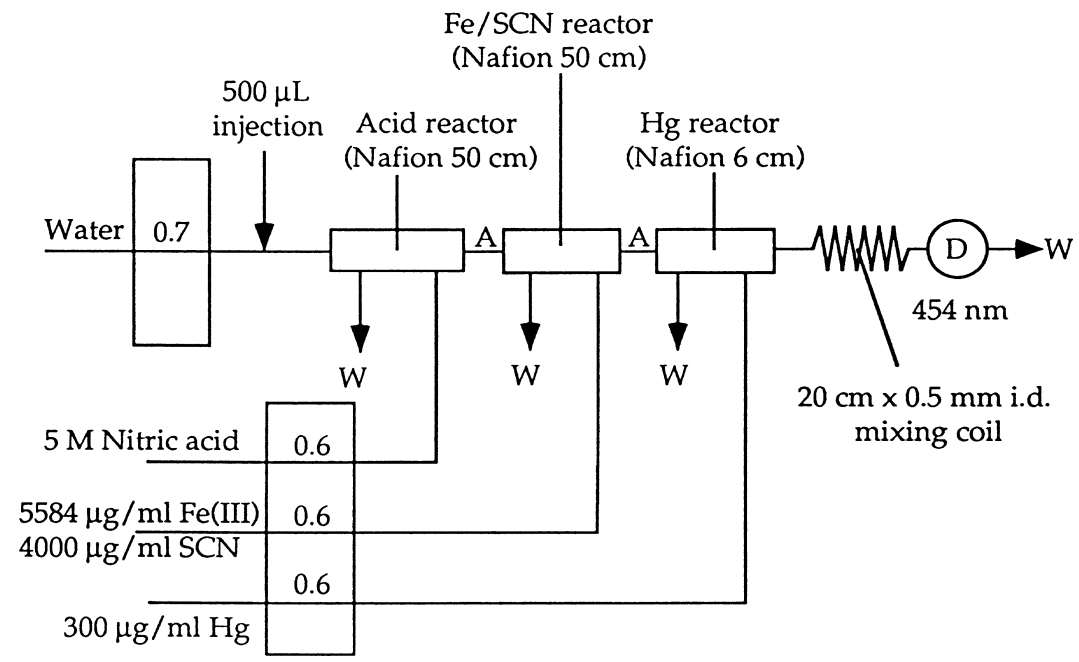

Fig. 2. Manifold for the determination of chloride with reagent introduction through Nafion membranes. A represents a $0.5 \mathrm{~mm}$ i.d. $\times 20 \mathrm{~cm}$ coiled Teflon tube. The flow rates are given on the pumps in $\mathrm{ml} \mathrm{min}^{-1}$. W is waste.

\subsection{Manifold design and operation}

The relevant parameters, discussed in the previous section, were adjusted to produce the maximum sensitivity, and the manifold developed is shown in Fig. 2. The reactors were connected by $20 \mathrm{~cm}$ of $0.5 \mathrm{~mm}$ i.d. coiled tubing. The waste lines on the donor streams were $0.3 \mathrm{~mm}$ i.d. tubing. The manifold was first flushed with water for $5 \mathrm{~min}$ to establish a baseline at $454 \mathrm{~nm}$. Acid and $\mathrm{Fe} / \mathrm{SCN}$ donor streams were then pumped while the absorbance of the acceptor stream was monitored at $454 \mathrm{~nm}$. When the absorbance had reached steady state (about absorbance 2), the mercury donor stream was pumped and the flow rate adjusted so that the concentration of the mercury donor stream produced a suitably low baseline absorbance.

\subsection{Validation of procedure}

Two water samples, Connecticut River water and UMass pond water, were analyzed for their chloride concentration by the procedure based on the membrane reagent introduction manifold and by EPA method 325.5, modified for FI. Calibration standards containing $0.0,1,2,3,4,5,10,15,20$ and $25 \mu \mathrm{g} \mathrm{ml}^{-1}$ chloride were used.

\section{Results and discussion}

\subsection{Acid introduction}

The results for the performance of the reactor are given in Table 2. For a donor flow of around $0.7 \mathrm{ml} \mathrm{min}^{-1}$, the $\mathrm{pH}$ could be changed from about 5 to just under 1 as the acceptor flow was changed from $1.2-0.49 \mathrm{ml} \mathrm{min}^{-1}$. It can also be seen, from the gravimetric measurement of the flow rates, that water was transferred across the membrane from "acceptor" to "donor" streams at a rate of about $140 \mu 1 \mathrm{~min}^{-1}$. Transport of $\mathrm{H}^{+}$across the Nafion membrane in this case is not due to ion exchange as there is negligible ionic strength in the acceptor. Rather, both protons and nitrate ions travel through the membrane in equal numbers. The concentration produced in the acceptor is limited by the "anion forbidden" concentration [19] for nitrate in the membrane used. Different types of Nafion have different properties, with some being more semi-permeable than others. In a situation where large concentrations of ions are present on one side, small amounts of the normally forbidden ions break through the membrane due to the large chemical potential gradient.

An acceptor flow rate of about $0.6 \mathrm{ml} \mathrm{min}^{-1}$ was chosen, as it produced an acid concentration of about $0.1 \mathrm{M}$; higher than required for the reaction but, 
Table 2

Flow rate measurements and $\mathrm{pH}$ values for a $50 \mathrm{~cm}$ Nafion reactor

\begin{tabular}{|c|c|c|c|c|c|c|}
\hline \multicolumn{2}{|c|}{ Donor flow rate $\left(\mathrm{ml} \mathrm{min}{ }^{-1}\right)$} & \multicolumn{2}{|c|}{ Acceptor flow rate $\left(\mathrm{ml} \mathrm{min}^{-1}\right)$} & \multirow{2}{*}{$\begin{array}{l}\text { Donor flow change } \\
\left(\mu 1 \min ^{-1}\right)\end{array}$} & \multirow{2}{*}{$\begin{array}{l}\text { Acceptor flow change } \\
\left(\mu 1 \min ^{-1}\right)\end{array}$} & \multirow[t]{2}{*}{$\mathrm{pH}$} \\
\hline In & Out & In & Out & & & \\
\hline 0.6770 & 0.6769 & 1.197 & 1.197 & 0 & 0 & $\sim 5.5$ \\
\hline 0.7543 & 0.8926 & 1.193 & 1.046 & +138 & -147 & 1.45 \\
\hline 0.7250 & 0.8605 & 0.9951 & 0.8541 & +136 & -141 & 1.35 \\
\hline 0.7235 & 0.8552 & 0.7233 & 0.5764 & +132 & -147 & 1.20 \\
\hline 0.7263 & 0.8539 & 0.4871 & 0.3523 & +128 & -135 & 0.95 \\
\hline
\end{tabular}

appropriate to allow cation exchange at the downstream reactors.

The transfer of water across the membrane did not produce any change in the concentration of a $100 \mu \mathrm{g} \mathrm{ml}^{-1}$ solution of chloride entering the reactor, and thus it is possible that some chloride is lost by transfer across the Nafion into the acid stream, though none was detected in the acid stream.

\subsection{Iron and thiocyanate introduction}

The concentrations of iron and thiocyanate in the acceptor stream of $0.1 \mathrm{M}$ acid at $0.6 \mathrm{ml} \mathrm{min}^{-1}$ for various flow rates of two different compositions of donor stream are shown in Table 3. As expected, iron(III) exchanged at a much higher rate than thiocyanate through the Nafion reactor. In the final manifold, the higher concentrations in the donor stream of $0.10 \mathrm{M}$ iron and $0.069 \mathrm{M}$ thiocyanate were used at a flow rate of $0.6 \mathrm{ml} \mathrm{min}{ }^{-1}$. This gave a concentration of thiocyanate close to that shown in Table 1, though the iron concentration was only about half the target value. No fluid transfer across the reactor was detected i.e. the flow rates in and out in the two streams were found to be equal within experimental error.

\subsection{Mercury introduction}

Table 4 shows the concentrations produced using a $1000 \mu \mathrm{g} \mathrm{ml}^{-1} \mathrm{Hg}(\mathrm{II})$ donor and a $0.1 \mathrm{M}$ nitric acid acceptor. As the concentrations produced using a

Table 3

Concentrations of iron(III) and thiocyanate produced in acceptor stream for a $50 \mathrm{~cm}$ Nafion cation exchange reactor

(a)

\begin{tabular}{lllll}
\hline Flow rate $\left(\mathrm{ml} \mathrm{min}^{-1}\right)$ & {$[\mathrm{SCN}] \mu \mathrm{g} \mathrm{ml}^{-1}$} & $\begin{array}{l}\mathrm{SCN} \text { permeation } \\
\text { rate }\left(\mu \mathrm{g} \mathrm{min}^{-1}\right)\end{array}$ & {$[\mathrm{Fe}] \mu \mathrm{g} \mathrm{ml} l^{-1}$} & $\begin{array}{l}\text { Fe permeation } \\
\text { rate }\left(\mu \mathrm{g} \mathrm{min}{ }^{-1}\right)\end{array}$ \\
\hline 1.16 & 10.4 & 12.1 & 225 & 261 \\
0.93 & 12.2 & 11 & 286 & 270 \\
0.71 & 15.6 & 11 & 366 & 260 \\
0.48 & 22.4 & 10 & 479 & 230 \\
\hline
\end{tabular}

(b)

\begin{tabular}{lllll}
\hline Flow rate $\left(\mathrm{ml} \mathrm{min}^{-1}\right)$ & {$[\mathrm{SCN}] \mu \mathrm{g} \mathrm{ml}^{-1}$} & $\begin{array}{l}\mathrm{SCN} \text { permeation } \\
\text { rate }\left(\mu \mathrm{g} \mathrm{min}^{-1}\right)\end{array}$ & {$[\mathrm{Fe}] \mu \mathrm{g} \mathrm{ml} l^{-1}$} & $\begin{array}{l}\text { Fe permeation } \\
\left.\text { rate }(\mu \mathrm{g} \mathrm{min})^{-1}\right)\end{array}$ \\
\hline 1.16 & 25.5 & 29.5 & 230 & 266 \\
0.93 & 28.6 & 27 & 283 & 260 \\
0.71 & 35.8 & 25 & 364 & 260 \\
0.48 & 44.6 & 21 & 454 & 220 \\
\hline
\end{tabular}

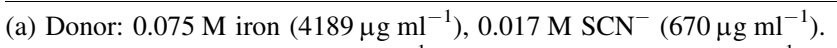

(b) Donor: $0.1 \mathrm{M}$ iron $\left(5584 \mu \mathrm{g} \mathrm{ml}^{-1}\right), 0.069 \mathrm{M} \mathrm{SCN}^{-}\left(4000 \mu \mathrm{g} \mathrm{ml}^{-1}\right)$. 
Table 4

Mercury(II) concentrations produced using a $50 \mathrm{~cm}$ Nafion cation exchange reactor

\begin{tabular}{|c|c|c|}
\hline 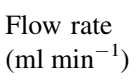 & {$[\mathrm{Hg}] \mu \mathrm{g} \mathrm{ml}^{-1}$} & $\begin{array}{l}\text { Hg permeation } \\
\text { rate }\left(\mu \mathrm{g} \min ^{-1}\right)\end{array}$ \\
\hline 1.15 & 281 & 324 \\
\hline 0.93 & 369 & 340 \\
\hline 0.70 & 495 & 350 \\
\hline 0.47 & 710 & 340 \\
\hline
\end{tabular}

$50 \mathrm{~cm}$ Nafion reactor were too high, a shorter $(6 \mathrm{~cm})$ reactor was made for the subsequent experiments, the final concentration in the donor stream was $300 \mu \mathrm{g} \mathrm{ml}^{-1}$. This brought the concentration of mercury in the acceptor stream down by about an order of magnitude to a value in line with the target value in Table 1 of $79 \mu \mathrm{g} \mathrm{ml}^{-1}$. Again, no fluid transfer across the reactor was detected.

\subsection{Validation of the procedure}

The requirement to have a slow flow of

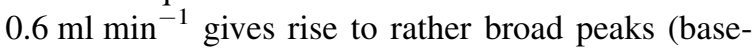
width appoximately $200 \mathrm{~s}$ ) with consequent low throughput. The calibration data obtained for standards up to $25 \mu \mathrm{g} \mathrm{ml}^{-1}$ are shown in Fig. 3 from which it can be seen that over this concentration range the calibration is decidedly curved, though still usable. This curvature is most likely due to the reagent composition being too low with respect to thiocyanate and too high with respect to acid, so that the formation of thiocyanic acid, HSCN, is a viable competitor reaction to the formation of $\mathrm{FeSCN}^{2+}$. The sensitivity, based on the $1 \mu \mathrm{g} \mathrm{ml}^{-1}$ standard, was 0.032 absorbance $\mu \mathrm{g}^{-1} \mathrm{ml}$, which compares quite favorably with that of an optimized double-line FI method of 0.043 absorbance $\mu \mathrm{g}^{-1} \mathrm{ml}$ [13]. The detection limit was estimated to be about $300 \mathrm{ng} \mathrm{ml}^{-1}$, a value which is considerably higher than those reported previously, even for FI procedures. The main factor contributing to the noise appeared to be mixing noise; pulsations in the flows in both donor and acceptor streams gave rise to pulsations in the concentrations of reagents delivered into the acceptor stream.

The results for the analyses of the water samples are given in Table 5 together with the associated 95\% confidence intervals, including the contribution from the uncertainty in fitting the calibration function to the points. In the case of the results from the membrane reactor manifold, these are unsymmetrical due to the curved nature of the calibration. It can be seen that the results obtained by the two methods are not significantly different i.e. as the $95 \%$ confidence intervals

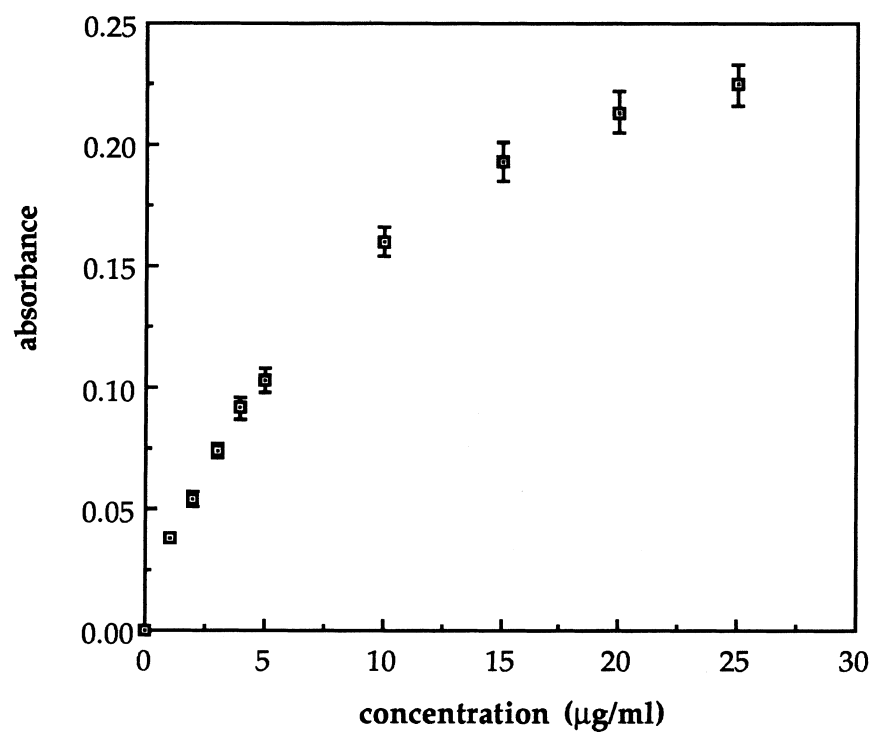

Fig. 3. Scatter plot of calibration data from $0-25 \mu \mathrm{g} \mathrm{ml}^{-1}$ chloride. 
Table 5

Results for the analysis of water samples

\begin{tabular}{lcr}
\hline Sample & \multicolumn{2}{c}{ Chloride concentration $\left(\mu \mathrm{g} \mathrm{ml}^{-1}\right)$} \\
\cline { 2 - 3 } & Membrane method & EPA method \\
\hline River water & $8(+2.22,-1.80)$ & $8( \pm 1.35)$ \\
Pond water & $47(+4.20,-4.05)$ & $50( \pm 6.71)$ \\
\hline
\end{tabular}

95\% Confidence intervals are shown in parentheses.

overlap, a $t$-test would show that the mean values were not significantly different.

\section{Conclusions}

The concept of reagent introduction across Nafion membranes has been demonstrated for the production of the "chloride reagent". The system is still not fully characterized in terms of the identification and elimination of mixing noise sources, though effects such as those due to valve switching and refractive index changes were not observed. The reagent composition was also sub-optimal, though this is less of a concern in that the goal was to develop a manifold for determinations at very low concentrations for which the sensitivity is adequate. The procedure would benefit from miniaturization, as this would increase the linear flow rate and help to improve radial mixing which is still predominantly by diffusion. Radial mixing might also be promoted by the insertion of inert beads or a crimped filament into the reactors. The function of the acid reactor needs further characterization, as it is not clear whether the analyte species was lost at this reactor. The expected increase in concentration due to the transfer of water across the membrane was not observed. The performance of the analogous system in which the reagents are prepared by immobilization on cation-exchange resins should be investigated.

\section{Acknowledgements}

Financial support for SJC from Pfizer, Groton, CT is gratefully acknowledged, as is the donation of Nafion reactors by Perma Pure.

\section{References}

[1] S.J. Chalk, J.F. Tyson, Anal. Chem. 66 (1994) 660.

[2] A. Daniel, D. Birot, M. Lehaitre, J. Poncin, Anal. Chim. Acta 308 (1995) 413.

[3] Flow Injection Analysis Based on Enzymes or Antibodies, R.D. Schmidt (Ed.), VCH, Weinheim 1991.

[4] F.J. Andrade, M.B. Tudino, O.E. Troccoli, Analyst 121 (1996) 613.

[5] K. Ueno, F. Sagara, K. Higashi, K. Yakata, I. Yoshida, D. Ishii, Anal. Chim. Acta 261 (1992) 241.

[6] W. Qin, Z. Zhang, C. Zhang, Analyst 122 (1997) 685.

[7] A. Trojanek, S. Bruckenstein, Anal. Chem. 58 (1986) 983.

[8] S.J. Chalk, J.F. Tyson, Talanta 41 (1994) 1797.

[9] H. Hwang, P.K. Dasgupta, Anal. Chem. 59 (1987) 1356.

[10] W.J. Williams, The Determination of Anions, Butterworths, London 1979, p. 307.

[11] D.M. Zall, D. Fisher, M.Q. Garner, Anal. Chem. 28 (1956) 1665.

[12] T.M. Florence, Y.J. Farrar, Anal. Chim. Acta 54 (1971) 373

[13] J.F. Tyson, A.G. Fogg, X. Wang, Quim. Anal. 8 (1989) 179.

[14] J.F. Van Staden, Fresenius' Z. Anal. Chem. 322 (1985) 36.

[15] J. Ruzicka, J.W.B. Stewart, E.A.G. Zagatto, Anal. Chim. Acta 81 (1976) 387.

[16] F.J. Krug, A.O. Jacintho, E.A.G. Zagatto, B.F. Reis, L.C.R. Pessenda, Anal. Chim. Acta 130 (1981) 409.

[17] S.M. Edmonds, N. Birnbaum, J. Am. Chem. Soc. 63 (1941) 1471

[18] H.E. Bent, C.L. French, J. Am. Chem. Soc. 63 (1941) 568.

[19] C.H. Hamann, V. Theile, S. Koter, J. Membr. Sci. 78 (1993) 147. 